ORIGINAL ARTICLE

\title{
Performance of Multiple Massive Transfusion Definitions in Trauma Patients
}

\author{
Daniela Burbano ${ }^{1}$, Julian Chica², Claudia P Orlas ${ }^{3}$, Fredy Ariza ${ }^{4}$, Ramiro Manzano ${ }^{5}$, Camilo Salazar ${ }^{6}$, Sandra Carvajal $^{7}$, \\ Carlos Ordonez ${ }^{8}$, Alberto Garcia ${ }^{9}$
}

\begin{abstract}
Introduction: Massive transfusion (MT) is defined as the administration of $\geq 10 \mathrm{U}$ of packed red blood cells (PRBCs) in 24 hours. Alternative definitions have been proposed which have not been compared regarding mortality or multiorgan failure (MOF). The objective is to compare the discriminative ability of proposed definitions of MT concerning mortality and MOF.

Materials and methods: Patients with trauma team activation in a level I trauma hospital of Cali, Colombia, between 2015 and 2017 were included. Demographics and trauma characteristics were evaluated. The following MT definitions were measured: $\geq 50 \mathrm{U}$ of total blood products in 24 hours (MT50-24), $\geq 6 \mathrm{U}$ of PRBCs in 6 hours (MT6-6), $\geq 10 \mathrm{U}$ of PRBCs in 6 hours (MT10-6), a combination of MT10-24 plus MT6-6 (MTcombi), $\geq 5 \mathrm{U}$ of PRBC in 4 hours (MT5-4), $\geq 4 \mathrm{U}$ of PRBC in 1 hour (MT4-1), and the critical administration threshold (CAT) which is $3 \mathrm{U}$ of PRBCs in 1 hour. The operative characteristics were calculated for each definition. Multiorgan failure was defined as a sequential organ failure assessment (SOFA) score of $\geq 6$ points.

Results: We included 394 subjects. A total of 266 (67\%) received at least 1 unit of PRBCs in the first 24 hours, from which trauma mechanism was penetrating in $84.6 \% ; 86.8 \%$ were male, with a median [interquartile range (IQR)] age of 29 (22-38) years and injury severity score (ISS) of 25 (25-29). A positive ABC score for massive transfusion score was positive in $87.2 \%$. Sensitivity and specificity were as follows: multiorgan failure: MT10-24 18.6\% and 98.2\%, MT6-6 34.3\% and 91.3\%, MTcombi 38.2\% and 91.3\%, MT5-4 38.2\% and 92.2\%, and MT4-1 48\% and 78.4\%. Mortality: MT10-24 40.6\% and 92.2\%, MT6-6 62.7\% and 82.6\%, MTcombi 64.4\% and 80.6\%, MT5-4 61\% and 81.1\% and MT4-1 71.1\% and 68.6\%. Conclusion: All definitions showed an association with a higher risk of mortality and MOF, generally with low sensitivity but high specificity. The MT definition of $\geq 10$ PRBCs in 24 hours should be revised.
\end{abstract}

Keywords: Blood transfusion, Emergency, Hemorrhage, Injury, Trauma.

\section{Abstract}

Introducción: Transfusión masiva (MT) se define como la administración de $\geq 10$ unidades (U) de glóbulos rojos empaquetados (PRBC) en 24 horas. Se han propuesto definiciones alternativas que no se han comparado con respecto a la mortalidad o la falla multiorgánica (MOF). El objetivo es comparar la capacidad discriminativa de las definiciones propuestas de MT con respecto a la mortalidad y la MOF.

Métodos: Se incluyeron pacientes que requirieron activación del equipo de trauma en un hospital de trauma Nivel I de Cali, Colombia entre 2015-2017. Se evaluaron las características demográficas y del trauma. Se midieron las siguientes definiciones de MT: $\geq 50$ U de hemoderivados totales en 24 horas (MT50-24), $\geq 6$ U de PRBC en 6 horas (MT6-6), $\geq 10$ U de PRBC en 6 horas (MT10-6), una combinación de MT10-24 más MT6-6 (MTcombi), $\geq 5 \mathrm{U}$ de PRBC en 4 horas (MT5-4), $\geq 4 \mathrm{U}$ de PRBC en 1 hora (MT4-1) y el umbral crítico de administración (CAT) que es 3 U de PRBC en 1 hora. Las características operativas se calcularon para cada definición. MOF se definió como una puntuación SOFA de $\geq 6$ puntos.

Resultados: Incluimos 394 sujetos. Un total de 266 (67\%) recibieron al menos 1 unidad de PRBC en las primeras 24 horas, de estos, el mecanismo de trauma era penetrante en el $84.6 \%$, el $86.8 \%$ eran hombres, con una mediana y RIQ de edad de 29 (22-38) años e ISS de 25 (25-29). El ABC fue positivo en $87.2 \%$. La sensibilidad, la especificidad fueron las siguientes: MOF: MT10-24 18.6\% y 98.2\%, MT6-6 34.3\% y $91.3 \%$, MTcombi $38.2 \%$ y $91.3 \%$, MT5-4 38.2\% y $92.2 \%$, MT4-1 48\% y $78.4 \%$. Mortalidad: MT10-24 40.6\% y $92.2 \%$, MT6-6 62.7\% y $82.6 \%$, MTcombi $64.4 \%$ y $80.6 \%$, MT5-4 61\% y $81.1 \%$, MT4-1 $71.1 \%$ y $68.6 \%$.

Conclusión: Todas las definiciones mostraron una asociación con un mayor riesgo de mortalidad y MOF, generalmente con baja sensibilidad pero alta especificidad. Se debe revisar la definición de MT de $\geq 10$ glóbulos rojos empaquetados (PRBC) en 24 horas.

Palabras clave: Emergencia, Hemorragia, Lesión, Transfusión de sangre, Trauma.

Panamerican Journal of Trauma, Critical Care \& Emergency Surgery (2020): 10.5005/jp-journals-10030-1275

\section{INTRODUCTION}

Trauma is the leading cause of death among adults up to the age of 45 years. ${ }^{1,2}$ The first hours after trauma are the most critical and deadliest; ${ }^{3}$ hemorrhagic shock is the second leading cause of death in the first 24 hours (early deaths), accounting for 30 to $40 \%$ of injury-related mortality. 4,5

In recent years, the understanding of resuscitation in trauma patients has been a major focus of the trauma literature. Evidence suggests that about 25 to $30 \%$ of severely injured patients are coagulopathic at the time of admission to the emergency department, ${ }^{6}$ and this condition has been referred to as acute
${ }^{1}$ Department of Cirugía Trauma y Emergencias, Fundación Valle del Lili, Cali, Valle del Cauca, Colombia

2,3,6,8,9 Department of Cirugía Trauma y Emergencias/Centro de investigaciones clínicas, Fundación Valle del Lili, Cali, Valle del Cauca, Colombia

${ }^{4}$ Department of Anestesiologia, Fundación Valle del Lili, Cali, Valle del Cauca, Colombia

${ }^{5}$ Centro de Investigaciones Clínicas, Fundación Valle del Lili, Cali, Valle del Cauca, Colombia

${ }^{7}$ Department of Urgencias, Fundación Valle del Lili, Cali, Valle del Cauca, Colombia

(C) The Author(s). 2020 Open Access This article is distributed under the terms of the Creative Commons Attribution 4.0 International License (https://creativecommons. org/licenses/by-nc/4.0/), which permits unrestricted use, distribution, and non-commercial reproduction in any medium, provided you give appropriate credit to the original author(s) and the source, provide a link to the Creative Commons license, and indicate if changes were made. The Creative Commons Public Domain Dedication waiver (http://creativecommons.org/publicdomain/zero/1.0/) applies to the data made available in this article, unless otherwise stated. 
traumatic coagulopathy (ATC). ${ }^{7}$ The ATC is usually present in patients with injury severity score (ISS) $\geq 25$ and has been associated with greater incidence of multi-organ failure (MOF), higher transfusion requirement, ${ }^{7}$ and increased mortality. ${ }^{6}$ Thus, understanding the intervention and management of ATC is an active area of research. ${ }^{8}$

Approximately $13-24 \%$ of trauma patients who receive blood transfusions will require high amounts of blood components and will fulfill the criteria for massive transfusion (MT) ${ }^{9,10}$ which is traditionally defined as the administration of $\geq 10 \mathrm{U}$ of packed red blood cells (PRBCs) in the first 24 hours (MT10-24). ${ }^{11-13}$ However, there is no actual agreement about this definition.

Traditionally, in the 1970s, MT was defined as the total replacement of a patient's circulatory volume in 24 hours, which is calculated as $5 \mathrm{~L}$ of blood or $10 \mathrm{U}$ of $500 \mathrm{cc}$ of whole blood (for an average $70 \mathrm{~kg} \mathrm{man)} .^{14-16}$ In the 1990s, the concept evolved to $10 \mathrm{U}$ of PRBCs arbitrarily. ${ }^{13}$ Literature has shown that mortality increases with the number of units of PRBCs transfused in 24 hours, but it has failed to demonstrate a threshold effect at 10 units or any other value. ${ }^{17}$ Additionally, this definition is susceptible to survival bias, and dilutes the cohort with inadequate patients, since some patients may receive large volumes over an extended period and remain physiologically normal.

Several authors have proposed alternative definitions trying to overcome the mentioned limitations of the traditional one. This study aimed to compare trauma and demographic characteristics along with blood product utilization between multiple definitions of MT at a level I trauma center in Cali, Colombia. Additionally, we sought to identify the definition that has a better performance predicting mortality and MOF. We hypothesized that the traditional MT definition underestimates patients with massive bleeding who died before reaching the threshold and that the more acute definitions better capture these patients with massive active bleeding.

\section{Materials and Methods}

We performed a retrospective review of civilian trauma cases between 2015 and 2017 in Fundación Valle del Lili, which is a level I trauma center in Cali, Colombia, with 510 beds and 80 adult intensive care units (ICUs), of which 10 are reserved for trauma patients.

Patients who were 18 years and older, who had the highest trauma team activation, had torso trauma, and required emergent surgery were included. Subjects who did not receive at least $1 \mathrm{U}$ of blood product were excluded.

Demographics, trauma characteristics, administered blood products, development of MOF, and hospital mortality were registered. Total amount of PRBCs transfused was defined as the amount of PRBCs given in the first 24 hours from admission to the emergency department. Multiorgan failure was defined as a total SOFA score of $\geq 6$ points.

The following MT definitions described in the literature were measured: $\geq 10 \mathrm{U}$ of PRBCs in 24 hours (MT10-24), ${ }^{11-13} \geq 50 \mathrm{U}$ of total blood products in 24 hours (MT50-24), ${ }^{18} \geq 6 \mathrm{U}$ of PRBCs in 6 hours (MT6-6), ${ }^{19} \geq 10$ U of PRBCs in 6 hours (MT10-6), ${ }^{20,21}$ a combination of MT10-24 plus MT6-6 (MTcombi), $\geq 5$ U of PRBCs in 4 hours (MT5-4), ${ }^{12}$ $\geq 4 \mathrm{U}$ of PRBCs in 1 hour (MT4-1), ${ }^{22}$ and the CAT which is $3 \mathrm{U}$ of PRBCs in 1 hour. ${ }^{23,24}$ Additionally, Savage et al. quantified the number of times CAT+ was reached, i.e., once (CAT1), twice (CAT2), or three times (CAT3). The operative characteristics regarding MOF and hospital mortality were calculated for each definition.
Corresponding Author: Daniela Burbano, Department of Cirugía Trauma y Emergencias, Fundación Valle del Lili, Cali, Valle del Cauca, Colombia, Phone: +57 3156161190, e-mail: danielaburbanoj94@hotmail.com

How to cite this article: Burbano D, Chica J, Orlas CP, et al. Performance of Multiple Massive Transfusion Definitions in Trauma Patients. Panam J Trauma Crit Care Emerg Surg 2020;9(1):61-66.

Source of support: Nil

Conflict of interest: None

The data were analyzed with STATA $15.1^{\circledR}$ (College Station TX). Categorical variables are presented as quantities and proportions, and the continuous variables as mean and standard deviation or median (IQR). Operative characteristics for each definition were calculated.

No institutional review board (IRB) or ethics board approval was required to perform this retrospective review, since this is a no-risk study according to the Colombian resolution number 8430 of 1993.

\section{Results}

Three hundred ninety-four subjects met the highest level of trauma team activation. A total of $266(67 \%)$ received at least 1 unit of PRBCs in the first 24 hours after admission and were included in the analysis. Of them, 231 (86.8\%) were male, with a median (IQR) age of 29 (22-38) years. The trauma mechanism was penetrating in 225 (84.6\%).

General information is presented in Table 1. The number of blood products used by every MT definition is shown in Table 2. Each definition was evaluated for mortality and MOF, and the results are presented in Tables 3 and 4, respectively. Fifty-eight (21.8\%)

Table 1: Demographic and clinical characteristics

\begin{tabular}{ll}
\hline Total, $n$ & 266 \\
\hline Male gender, $n$ (\%) & $231(86.84)$ \\
Age, median (IQR) & $29(22-38)$ \\
Trauma mechanism & \\
$\quad$ Penetrating, $n$ (\%) & $225(84.59)$ \\
$\quad$ Blunt, $n$ (\%) & $41(15.41)$ \\
Heart rate, beats/minute, median (IQR) & $104(83-122)$ \\
SBP, mm Hg, median (IQR) & $88(60-110)$ \\
GCS, median (IQR) & $15(8-15)$ \\
Motor GCS, median (IQR) & $6(5-6)$ \\
ISS, median (IQR) & $25(25-29)$ \\
ABC+, $n$ (\%) & $232(87.22)$ \\
Lactate mmol/L, median (IQR) & $4.62(2.9-7.97)$ \\
Hemoglobin, g/dL, median (IQR) & $10.6(8.1-12.8)$ \\
BE, mmol/L, median (IQR) & $-8.8(-13$ to -5.6) \\
pH, median (IQR) & $7.22(7.10-7.30)$ \\
Aortic occlusion & \\
$\quad$ Clamp, $n$ (\%) & $45(16.92)$ \\
REBOA, $n$ (\%) & $43(16.17)$ \\
Vasopressors, $n$ (\%) & $227(85.34)$ \\
Multiple vasopressors, $n$ (\%) & $61(22.93)$ \\
Total SOFA, mean (IQR) & $5(3-8)$ \\
In-hospital deaths, $n$ (\%) & $58(21.80)$ \\
\hline
\end{tabular}

SPB, systolic blood pressure; GCS, Glasgow coma scale; ISS, injury severity score; $A B C+$, positive $A B C$ score for massive transfusion; $B E$, base excess; REBOA, resuscitative endovascular balloon occlusion of the aorta; SOFA, sequential organ failure assessment 


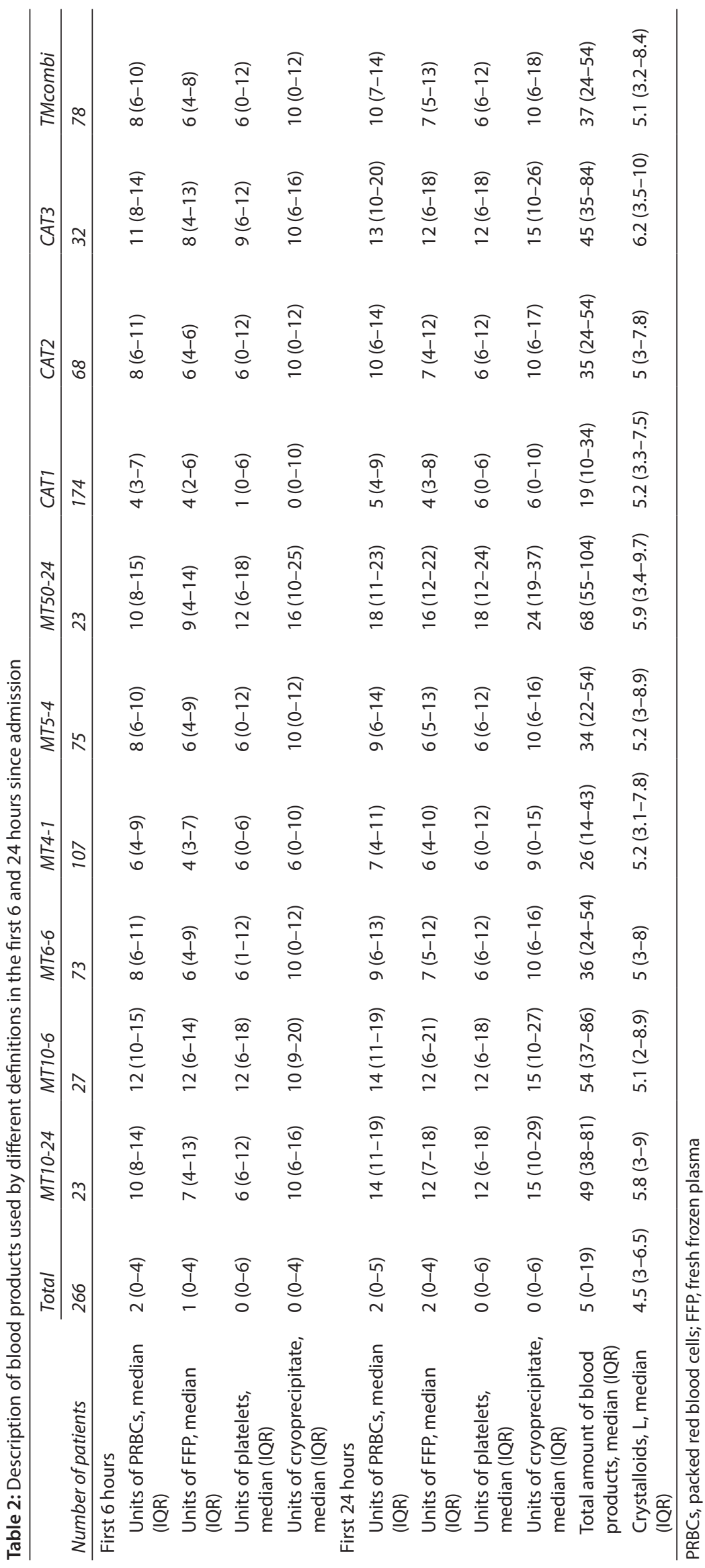


Massive Transfusion in Trauma: Is it Time for a New Definition?

Table 3: Comparison of different definitions of massive transfusion regarding mortality

\begin{tabular}{|c|c|c|c|c|c|c|c|c|}
\hline & No. & Deaths, $n(\%)$ & Sensitivity (\%) & Specificity (\%) & $L R+$ & $L R-$ & $\begin{array}{l}\text { (\%) Correct } \\
\text { classification }\end{array}$ & $O R(C I)$ \\
\hline MT50-24 & 23 & $16(69.57)$ & 27.12 & 96.62 & 8.02 & 0.75 & 81.20 & $10.63(3.80-32.11)$ \\
\hline MT10-24 & 40 & $24(60)$ & 40.68 & 92.27 & 5.26 & 0.64 & 80.83 & $8.19(3.71-18.14)$ \\
\hline MT6-6 & 73 & $37(50.68)$ & 62.71 & 82.61 & 3.61 & 0.45 & 78.20 & 7.99 (4.02-15.93) \\
\hline MT10-6 & 27 & $21(77.78)$ & 35.59 & 97.10 & 12.27 & 0.66 & 83.46 & $18.51(6.57-58.88)$ \\
\hline MTcombi & 78 & $38(48.72)$ & 64.41 & 80.68 & 3.33 & 0.44 & 77.07 & $7.55(3.82-15.02)$ \\
\hline MT5-4 & 75 & $36(48)$ & 61.02 & 81.16 & 3.24 & 0.48 & 76.69 & $6.74(3.43-13.29)$ \\
\hline MT4-1 & 107 & $42(39.25)$ & 71.19 & 68.60 & 2.27 & 0.42 & 69.17 & $5.40(2.75-10.84)$ \\
\hline CAT1 & 174 & 49 (28.16) & 69.49 & 44.44 & 1.25 & 0.69 & 50.00 & $3.21(1.50-7.50)$ \\
\hline CAT2 & 68 & $30(44.12)$ & 50.85 & 81.64 & 2.77 & 0.6 & 74.81 & $4.60(2.36-8.85)$ \\
\hline CAT3 & 32 & $21(65.62)$ & 35.59 & 94.69 & 6.7 & 0.68 & 81.58 & $9.85(4.10-24.32)$ \\
\hline
\end{tabular}

Fifty units of blood products in 24 hours (MT50-24), 10 units of PRBCs in 24 (MT10-24), 6 units of PRBCs in 6 hours (MT6-6), 10 units of PRBCs in 6 hours (MT10-6), the combination of MT10-24 and MT6-6 (MTcombi), 5 units of PRBCs in 4 hours (MT5-4), 4 units of PRBCs in 1 hour (MT4-1), 3 units of PRBCs in 1 hour in the first 24 hours (CAT1), CAT + in two occasions in the first 24 hours (CAT2), CAT + in three occasions in the first 24 hours (CAT3). Likelihood ratio $+(\mathrm{LR}+)$, likelihood ratio - (LR-), odds ratio (OR), confidence interval (Cl)

Table 4: Comparison of different definitions of massive transfusion regarding multiorgan failure

\begin{tabular}{lclllllll}
\hline & & & & & & & \multicolumn{2}{c}{$\begin{array}{l}\text { (\%) Correct } \\
\text { classification }\end{array}$} \\
\hline MT50-24 & 23 & $13(56.52)$ & 12.75 & 100 & - & 0.87 & 59.17 & - \\
MT10-24 & 40 & $19(47.5)$ & 18.63 & 98.28 & 10.8 & 0.82 & 61.01 & $13.05(2.98-117.45)$ \\
MT6-6 & 73 & $35(47.94)$ & 34.31 & 91.38 & 3.98 & 0.71 & 64.68 & $5.54(2.46-13.29)$ \\
MT10-6 & 27 & $11(40.74)$ & 10.78 & 100 & - & 0.89 & 58.26 & - \\
MTcombi & 78 & $39(50)$ & 38.24 & 91.38 & 4.44 & 0.68 & 66.51 & $6.56(2.94-15.66)$ \\
MT5-4 & 75 & $39(52)$ & 38.24 & 92.24 & 4.93 & 0.677 & 66.97 & $7.36(3.21-18.29)$ \\
MT4-1 & 107 & $49(45.79)$ & 48.04 & 78.45 & 2.23 & 0.66 & 64.22 & $3.36(1.80-6.35)$ \\
CAT1 & 174 & $78(44.83)$ & 68.63 & 54.31 & 1.5 & 0.58 & 61.01 & $3.36(1.81-6.33)$ \\
CAT2 & 68 & $32(47.06)$ & 31.37 & 90.52 & 3.31 & 0.76 & 62.84 & $4.36(1.97-10.19)$ \\
CAT3 & 32 & $15(46.88)$ & 14.71 & 100 & - & 0.85 & 60.09 & - \\
\hline
\end{tabular}

Fifty units of blood products in 24 hours (MT50-24), 10 units of PRBCs in 24 (MT10-24), 6 units of PRBCs in 6 hours (MT6-6), 10 units of PRBCs in 6 hours (MT10-6), the combination of MT10-24 and MT6-6 (MTcombi), 5 units of PRBCs in 4 hours (MT5-4), 4 units of PRBCs in 1 hour (MT4-1), 3 units of PRBCs in 1 hour in the first 24 hours (CAT1), CAT + in two occasions in the first 24 hours (CAT2), and CAT + in three occasions in the first 24 hours (CAT3). Likelihood ratio $+(\mathrm{LR}+)$, likelihood ratio - $(\mathrm{LR}-)$, odds ratio $(\mathrm{OR})$, confidence interval $(\mathrm{Cl})$

Table 5: Causes of death among patients receiving at least 1 unit of packed red blood cells

\begin{tabular}{ll}
\hline Cause of death & Deaths (total 58) (\%) \\
\hline Hemorrhage & $43(74.13)$ \\
CNS trauma & $7(12.06)$ \\
Cardiac tamponade & $1(1.72)$ \\
Neurogenic/spinal shock & $1(1.72)$ \\
MOF & $6(10.34)$ \\
\hline
\end{tabular}

CNS, central nervous system; MOF, multi-organ failure

patients died, with hemorrhage as the most common cause in 43 (74\%) patients followed by central nervous system (CNS) trauma in 7 (12\%) as shown in Table 5.

The traditional definition MT10-24 had a sensitivity of $40.68 \%$ and specificity of $92.27 \%$ for mortality. Among the other definitions, MT6- 6 had a sensitivity of $62.71 \%$ and specificity of $82.61 \%$, MTcombi had a sensitivity of $64.41 \%$ and a specificity of $80.68 \%$, MT5-4 had a sensitivity of $61.02 \%$ and a specificity of $81.16 \%$, and MT4-1 had the highest sensitivity of $71.19 \%$ and a specificity of $68.6 \%$, which seemed to be more advantageous than MT10-24. Both MT10-6 and MT50-24 had the highest specificities with $97.1 \%$ and $96.62 \%$, respectively, but have the lowest sensitivities with $35.59 \%$ and $27.12 \%$.

Regarding MOF, MT10-24 had a sensitivity of $18.63 \%$ and a specificity of $98.28 \%$. But other definitions seem to outperform MT10-24: MT5-4 had a sensitivity of $38.24 \%$ and a specificity of $92.24 \%$, MT6-6 had a sensitivity of $34.31 \%$ and a specificity of $91.38 \%$, MTcombi had a sensitivity of $38.24 \%$ and a specificity of $92.24 \%$, and MT4-1 had a sensitivity of $48.04 \%$ and a specificity of $78.45 \%$. The highest specificities, i.e., $100 \%$ were observed in MT50-24, MT10-6, and CAT3, but very low sensitivity of $12.75 \%$, $10.78 \%$, and $14.71 \%$, respectively. Higher sensitivity, i.e., $68.63 \%$, was observed in CAT1 but with a low specificity of $54.31 \%$.

In respect to likelihood ratio $+(L R+)$, the ones that performed best for mortality were MT10-6 and MT50-24 with an LR+ of 12.27 and 8.02 , respectively. And for MOF, the traditional definition of MT10-24 performed best with an LR+ 10.8 followed by MT5- 4 with an LR+ 4.93.

Regarding the percentage for correct classification, for mortality, the definition that performed best was MT10-6 at $83.46 \%$, 
followed by CAT3 at $81.58 \%$ and MT50-24 at $81.2 \%$. For MOF, the definition that performed best was MT5-4 at $66.97 \%$ followed by MTcombi at $66.51 \%$ and MT6-6 at $64.68 \%$.

Lastly, regarding the odds ratio (OR) for mortality, the highest were MT10-6, TM50-24, and CAT3 with an OR of 18.51, 10.63, and 9.85, respectively. And for MOF the highest were MT10-24, TM5-4, and MTcombi with an OR of 13.05, 7.36, and 6.56, respectively.

\section{Discussion}

The traditional definition of MT10-24 has been used since the $1990 \mathrm{~s}^{13}$ but the model of blood transfusion has changed dramatically over the last 20 years. Recent literature suggests the ideal transfusion ratio of PRBC-FFC is to be as close as possible to $1: 1^{10,25-27}$ and the development of damage control determines that the early use of blood product is a critical component of the resuscitation of trauma patients, along with permissive hypotension, prompt control of the bleeding, and contamination to continue resuscitation in the ICU. ${ }^{28}$ Additionally, goals of resuscitation have shifted to low systolic blood pressure (SBP), between $80 \mathrm{~mm} \mathrm{Hg}$ and $90 \mathrm{~mm}$ $\mathrm{Hg}$, prior bleeding control, ${ }^{29}$ and tolerating lower hemoglobin concentrations between $7.0 \mathrm{~g} / \mathrm{dL}$ and $9.0 \mathrm{~g} / \mathrm{dL}$ in the critically ill and trauma patients. ${ }^{29,30}$ All of these conducts and considerations are associated with the overall less blood utilization ${ }^{26,31}$ and probably is the reason why there has been a downward trend through the years of patients meeting the traditional definition of MT10-24. ${ }^{32}$

Furthermore, the cost of a unit of PRBCs has increased in previous years, ${ }^{18,33}$ and the availability might be challenging, especially for developing countries, making it a scarce resource. Therefore, some physicians might have a restrictive attitude toward transfusion in trauma patients and withhold the amount of unit of PRBCs for the sake of proper resource distribution.

Considering that the development of MT guidelines is based on MT definition, its definition needs to be representative regarding patients who undergo massive hemorrhage, since ultimately, this is the group that benefits from this strategy. And it is of great importance to have an actual definition that represents this population because the wrong definition can lead to inconsistent information, as Mitra et al. has demonstrated that after stratification by two different definitions of MT, the analysis could result in contradictory conclusions. ${ }^{12}$

To our knowledge, we are the first group to compare multiple proposed MT definitions found in the literature regarding mortality and MOF, since most authors who attend this issue limit to one new definition. Moren et al. compared MT4-1 with MT10-24 and found that with MT4-1 a subset of patients are identified who are at elevated risk of death that are not identified by the traditional MT definition. ${ }^{22}$ However, when comparing them among other definitions, the performance of MT4-1 regarding mortality and MOF was overshadowed.

In 2015, Savage et al. contrasted CAT and MT10-24 and found the groups were very similar regarding demographics, ISS, admission laboratory values, and vital signs, and that the CAT status remains a strong predictor of death when comparing CAT+ and CAT-. However, they did not compare mortality of CAT vs MT10-24. ${ }^{24}$ In our analysis, CAT+ had the best sensitivity for MOF and the second best for mortality, but with one of the lowest specificities, LR+, OR, and percentage of correct classification in both cases.

The definition of MT5-4 was proposed by Mitra et al. in 2011, where they compared both definitions and proved that there was no significant difference in patient demographics and outcome, but significant differences were observed in transfusion practice and that the acute definition excludes a group of patients who were significantly less severely injured, had less deranged vital signs, and received a significantly lower volume of PRBC transfusion in the first 4 hours. ${ }^{12}$ However, they did not compare MT5-4 and MT10-24 regarding mortality and MOF. In our study, MT5-4 had a good performance for MOF prediction with a good specificity, an acceptable sensitivity, the second best LR+ and OR with a $66.97 \%$ of correct classification. The performance for mortality of MT5-4 was not optimal, with an acceptable sensitivity, specificity, and percentage of correct classification but a low LR+ and OR.

Regarding MTcombi, for MOF it had a similar sensitivity, specificity, and percentage of correct classification as MT5-4 and an acceptable LR+ and OR. For mortality, it had a similar specificity as MT5-4 but a slightly higher sensitivity, LR+, OR, and an acceptable percentage of correct classification of $77.07 \%$.

Lastly, MT6-6 had the same specificity as MTcombi but lower sensitivity, LR+, OR, and percentage of correct classification for MOF. With regard to mortality, it had a slightly better LR+, OR, and percentage of correct classification than MTcombi and MT5-4, a specificity of $82.61 \%$ and an acceptable sensitivity of $62.71 \%$.

Generally, the definitions tend to have a better performance regarding MOF, but with mortality they fall short. There is no perfect definition for MT based on our results. But the definitions that might be the most consistent considering both mortality and MOF are MT5-4, MTcombi, and MT6-6, as these definitions were persistently among the ones with the most acceptable values regarding sensitivity, specificity, LR+, percentage of correct classification, and OR.

It is difficult to determine the definition of MT based on these results, but the traditional definition of MT10-24 falls short and performs poorly compared to other definitions, perhaps because MT10-24 includes patients who are relatively stable at admission to the emergency department and were transfused later in the day. The characteristic of the definitions that outperformed the traditional MT definition is that they all consist of a shorter time interval with lower number of PRBCs. The advantage of the acute definitions is that they possibly account for critically ill patients who died earlier or have an aggressive initial resuscitation and prompt bleeding control. Therefore, we consider that new guidelines should reconsider the definition or definitions used for MT for their process of selection and evaluation.

This study has potential limitations. First, our population consists of mostly penetrating trauma, since this is the principal injury mechanism of trauma patients in our region, but elsewhere, blunt injury is the first traumatic mechanism. The second limitation concerns the number of patients since we have a small study population, as we can see only a small number fulfill the criteria for each one of the definitions. Regarding these limitations, we consider this an important first step to an unsolved and controversial issue. We believe further comparison with a bigger sample and perhaps different outcomes are required.

\section{CONCLUSION}

The traditional definition of MT10-24 falls short and performs poorly compared to other definitions. It seems that a definition that consists of a shorter time interval and lower number of PRBCs is more accurate in predicting MOF and mortality. The definitions that had a better performance are MT5-4, MTcombi, and MT6-6, but further studies are require to determine the ideal MT definition, 
perhaps considering to contrast the definitions with coagulopathy found in each patient.

\section{References}

1. Cdc.gov. (2018). [online] Available at: https://www.cdc.gov/ injury/images/lc-charts/leading_causes_of_death_by_age_ group_2017_1100w850h.jpg [Accessed 21 Aug. 2019].

2. Rodríguez-García J, Peñaloza-Quintero R, Amaya-Lara J. Estimación de la carga global de enfermedad en Colombia 2012: nuevos aspectos metodológicos. Revista de Salud Pública 2017;19(2):235-240. DOI: 10.15446/rsap.v19n2.66179.

3. Acosta JA, Yang JC, Winchell RJ, et al. Lethal injuries and time to death in a level I trauma center. J Am Coll Surg 1998;186(528-533):528-533. DOI: 10.1016/s1072-7515(98)00082-9.

4. Cotton BA, Gunter OL, Isbell J, et al. Damage control hematology: the impact of a trauma exsanguination protocol on survival and blood product utilization. J Trauma 2008;64(5):1177-1183. DOI: 10.1097/ TA.0b013e31816c5c80.

5. Kauvar D, Lefering R, Wade C. Impact of hemorrhage on trauma outcome: an overview of epidemiology, clinical presentations, and therapeutic considerations. J Trauma 2006;60(Suppl):S3-S11. DOI: 10.1097/01.ta.0000199961.02677.19.

6. Brohi K, Singh J, Heron M, et al. Acute traumatic coagulopathy. J Trauma 2003;54(6):1127-1130. DOI: 10.1097/01.TA.0000069184. 82147.06.

7. Maegele $M$, Spinella $P$, Schöchl $H$. The acute coagulopathy of trauma. Shock 2012;38(5):450-458. DOI: 10.1097/SHK.0b013e31826dbd23.

8. McDaniel L, Etchill E, Raval J, et al. State of the art: massive transfusion. Transfus Med 2014;24(3):138-144. DOI: 10.1111/tme.12125.

9. Vogt K, Van Koughnett J, Dubois L, et al. The use of trauma transfusion pathways for blood component transfusion in the civilian population: a systematic review and meta-analysis*. Transfus Med 2012;22(3):156166. DOI: 10.1111/j.1365-3148.2012.01150.x.

10. Holcomb JB, del Junco DJ, Fox EE, et al. The prospective, observational, multicenter, major trauma transfusion (PROMMTT) study. JAMA Surg 2013;148(2):127. DOI: 10.1001/2013.jamasurg.387.

11. Shaz B, Dente $C$, Harris $R$, et al. Transfusion management of trauma patients. Anesth Analg 2009;108(6):1760-1768. DOI: 10.1213/ ane.0b013e3181a0b6c6.

12. Mitra B, Cameron P, Gruen R, et al. The definition of massive transfusion in trauma. Europ J Emerg Med 2011;18(3):137-142. DOI: 10.1097/MEJ.0b013e328342310e.

13. Cosgriff N, Moore E, Sauaia A, et al. Predicting life-threatening coagulopathy in the massively transfused trauma patient. J Trauma 1997;42(5):857-862. DOI: 10.1097/00005373-19970500000016.

14. Wilson R, Mammen E, Walt A. Eight years of experience with massive blood transfusions. J Trauma 1971;11(4):275-285. DOI: 10.1097/00005373-197104000-00001.

15. Lim R, Olcott IVC, Robinson A, et al. Platelet response and coagulation changes following massive blood replacement. J Trauma 1973;13(7):577-582. DOI: 10.1097/00005373-19730700000001.

16. Beal R. The rational use of blood. Aust NZ Surg 1976;46(4):309-313. DOI: 10.1111/j.1445-2197.1976.tb03239.x.
17. Stanworth SJ, Morris TP, Gaarder C, et al. Reappraising the concept of massive transfusion in trauma. Crit Care 2010;14(6):R239. DOI: 10.1186/ cc9394.

18. Vaslef S, Knudsen N, Neligan P, et al. Massive transfusion exceeding 50 units of blood products in trauma patients. J Trauma 2002;53(2): 291-296. DOI: 10.1097/00005373-200208000-00017.

19. Hodgman El, Cripps MW, Mina MJ, et al. External validation of a smartphone app model to predict the need for massive transfusion using five different definitions. J Traum Acut Care Surg 2018;84(2):397-402. DOI: 10.1097/TA.0000000000001756.

20. Kashuk JL, Moore EE, Johnson JL, et al. Postinjury life threatening coagulopathy: is 1:1 fresh frozen plasma: packed red blood cells the answer? J Trauma 2008;65(2):261-271. DOI: 10.1097/ TA.0b013e31817de3e1.

21. Moore FA, Nelson T, McKinley BA, et al. Massive transfusion in trauma patients: tissue hemoglobin oxygen saturation predicts poor outcome. J Trauma 2008;64(4):1010-1023. DOI: 10.1097/ TA.0b013e31816a2417.

22. Moren AM, Hamptom D, Diggs $B$, et al. Recursive partitioning identifies greater than $4 \mathrm{U}$ of packed red blood cells per hour as an improved massive transfusion definition. J Traum Acut Care Surg 2015;79(6):920-924. DOI: 10.1097/TA.0000000000000830.

23. Savage $S$, Zarzaur B, Croce $M$, et al. Redefining massive transfusion when every second counts. J Traum Acut Care Surg 2013;74(2): 396-402. DOI: 10.1097/TA.0b013e31827a3639.

24. Savage S, Sumislawski J, Zarzaur B, et al. The new metric to define large-volume hemorrhage. J Trauma Acute Care Surg 2015;78(2): 224-230. DOI: 10.1097/TA.0000000000000502.

25. Teixeira PGR, Inaba K, Shulman I, et al. Impact of plasma transfusion in massively transfused trauma patients. J Trauma 2009;66(3):693-697. DOI: 10.1097/TA.0b013e31817e5c77.

26. Sperry JL, Ochoa JB, Gunn SR, et al. An FFP:PRBC transfusion ratio $\geq 1: 1.5$ is associated with $A$ lower risk of mortality after massive transfusion. J Trauma 2008;65(5):986-993. DOI: 10.1097/ TA.0b013e3181878028.

27. Holcomb JB, Tilley BC, Baraniuk S, et al. Transfusion of plasma, platelets, and red blood cells in a 1:1:1 vs a 1:1:2 ratio and mortality in patients with severe trauma. JAMA 2015;313(5):471. DOI: 10.1001/ jama.2015.12.

28. Cap AP, Pidcoke HF, Spinella P, et al. Damage control resuscitation. Mil Med 2018;183(Suppl. 2):36-43. DOI: 10.1093/milmed/usy112.

29. Spahn DR, Bouillon B, Cerny V, et al. The european guideline on management of major bleeding and coagulopathy following trauma: fifth edition. Crit Care 2019;23(1):98. DOI: 10.1186/s13054-019-2347-3.

30. Garcia A. Critical care issues in the early management of severe trauma. Surg Clin Nor Am 2006;86(6):1359-1387. DOI: 10.1016/j. suc.2006.07.004.

31. Rotondo MF, Schwab CW, McGonigal MD, et al. Damage control. J Trauma 1993;35(3):375-383. DOI: 10.1097/00005373-19930900000008.

32. Kautza BC, Cohen MJ, Cuschieri J, et al. Changes in massive transfusion over time. J Traum Acut Care Surg 2012;72(1):106-111. DOI: 10.1097/ TA.0b013e3182410a3c.

33. Amin M, Fergusson D, Wilson $K$, et al. The societal unit cost of allogenic red blood cells and red blood cell transfusion in Canada. Transfusion 2004;44(10):1479-1486. DOI: 10.1111/j.1537-2995.2004.04065.x. 